\title{
AVALIAÇÃO DA INSERÇÃO PRECOCE DE ESTUDANTES UNIVERSITÁRIOS EM SERVIÇOS DE SAÚDE
}

\author{
EVALUATION OF THE INGRESSION OF UNIVERSITY STUDENTS IN \\ HEALTH SERVICES \\ EVALUACIÓN DEL INGRESO DE ESTUDIANTES UNIVERSITARIOS EN \\ LOS SERVICIOS DE SALUD
}

\author{
Maria Girlene Martins ${ }^{\prime}$ \\ Rosenilce Mourão Gontijo Resende ${ }^{2}$ \\ Paulo Sergio Carneiro Miranda ${ }^{3}$ \\ Itamar Tatuhy Sardinha Pinto ${ }^{4}$
}

REUMO:Os autores analisam a inserção de alunos da disciplina de Epidemiologia, do segundo período do curso de graduação em Enfermagem nos Serviços de Saúde como método de ensinoaprendizagem. O estudo foi desenvolvido em 17 centros de saúde com um total de 53 alunos, num periodo de 5 meses, em uma freqüência de um turno diário semanal, na cidade de Divinópolis, Minas Gerais, Brasil. Concluiu-se que desde que se defina com precisão as competências e limites da atuação do estudante ("o que pode/não pode ser feito pelos alunos em Serviço") nunca a inserção será precoce, pois estará adaptada a capacidade do aluno.

PALAVRAS-CHAVE: avaliação, acadêmicos de enfermagem, Serviços de Saúde

\section{INTRODUÇÃO}

A inserção de estudantes universitários em serviço como método de ensino-aprendizagem em Saúde vem sendo objeto de reflexão em Baptista e Silva (1998), de investigação em Correa (1991) e de propostas em De Salazar (1999), há algum tempo. A Rede de Instituições de Educação em Saúde de Orientação Comunitária (NETWORK), ao nivel internacional e a Revista "Olho Mágico", do Centro das Ciências da Saúde, de Londrina, ao nivel nacional, entre outras instituições, vêm procurando divulgar estas discussões. No entanto, certas questões que se colocavam no início dos estudos ainda mantém sua atualidade. Questões como: Quando inserilos ? Como inseri-los ? Que estratégia usar para evitar a dicotomia "Teoria - Prática" ? Como não prejudicar o funcionamento normal do Serviço (pela inserção precoce de alunos) e, pelo contrário, aprimorá-los ? Como não transformar a prática em uma experiência artificial ? Como evitar as "experiências piloto", mas sim, reproduzi-las, socializa-las ?

Estes desafios foram enfrentados ao ministrar-se a disciplina de Epidemiologia, prevista curricularmente para $\circ 2^{\circ}$. periodo do primeiro ano do referido curso. A disciplina, lecionada no segundo semestre de 1999, tem a carga horária de 90 horas, dividida em 36 horas teóricas e 54

${ }^{1}$ Enfermeira e Mestre.Coordenadora do Curso de Enfermagem do Instituto de Ensino e Pesquisa de Divinópolis (INESP/UEMG).

${ }^{2}$ Enfermeira. Coordenadora das Ações Básicas de Saúde e Gerencia de Projetos da Secretaria Municipal de Saúde de Divinópolis (SEMUSA).

${ }^{3}$ Médico e Doutor. Departamento de Medicina Preventiva e Social da Faculdade de Medicina da Universidade Federal de Minas Gerais.

${ }^{4}$ Médico e Doutor. Departamento de Medicina Preventiva e Social da Faculdade de Medicina da Universidade Federal de Minas Gerais 
horas práticas e foi oferecida para um total de 53 alunos. As aulas da disciplina foram marcadas para todas as sextas-feiras, no horário de $07: 00$ às 12:00 horas, no periodo compreendido entre 27 de agosto e 17 de dezembro. Com o respaldo da Coordenação do Curso, das Ações Básicas da SEMUSA, e das contribuições do Prof. Itamar Tatuhy realizou-se este trabalho e o presente artigo.

A proposta da Instituição é que a disciplina deveria ser conduzida por apenas 1 (um) professor, numa relação (problemática) de 1 professor/ 53 alunos. Em face da situação que se apresentava - 1 professor/ 53 alunos, durante 05 horas seguidas, uma vez por semana - avaliouse a possibilidade de inserir, precocemente, os alunos nos Serviços de Saúde, dentro de um método de ensino-aprendizagem, com os seguintes objetivos gerais:

1. Ministrar o curso de Epidemiologia baseando-nos na ementa prevista e no programa proposto.

2. Avaliar a inserção precoce de estudantes universitários nos Serviços de Saúde.

Como objetivos específicos, buscou-se obter respostas sobre o que muda no estudante com a sua inserção precoce nos Serviços de Saúde em relação:

- a imagem feita sobre o Serviço de Saúde,

- a atuação da enfermagem na atenção básica de saúde,

- ao conceito de Saúde-Doença,

- aos conceitos epidemiológicos

\section{METODOLOGIA}

Considerando método como o caminho escolhido para alcançar um objetivo, o primeiro passo do método foi o estabelecimento de pré-condições para a inserção dos universitários nos Serviços de Saúde. Estas constaram da concordância da coordenação do curso com a proposta que se esboçava, do apoio dos alunos, do respaldo e suporte da direção dos Serviços de Saúde. Esta última condição foi conseguida após reunião e discussão com o Colegiado Diretivo da SEMUSA, formado pelo Secretário de Saúde, assessores diretos e gerentes dos Centros de Saúde e Unidades do Programa de Saúde da Familia (PSF). O estabelecimento destas précondiçōes, que expressam a vontade politica dos envolvidos no desenvolvimento do projeto, foi fundamental para o desenrolar da proposta.

O segundo passo foi definir, com a equipe diretiva da SEMUSA/Gerentes das Unidades, quais Centros de Saúde/PSF serviriam como campo de ensino-aprendizagem da disciplina e quais as atividades da área de epidemiologia - que são desenvolvidas em todas as unidades que poderiam ser realizadas pelos alunos sob a supervisão do pessoal técnico dos Centros/ PSFs. A definição destas atividades, limites e competências é fundamental para a padronização de um ensino-aprendizagem, para o resguardo da instituição, dos alunos e da população. O terceiro passo foi definir as equipes de alunos por Unidades de Saúde (em média, 03 alunos por Unidade), quando foi considerado o acesso e a proximidade da Unidade das residências dos alunos.

A etapa seguinte foi estabelecer o horário das atividades no Serviço - de 07:00 às 10:00 horas - e das aulas teóricas, no INESP - de 10:30 às 12:00 horas, permitindo-se, assim um tempo de 30 minutos para o deslocamento dos alunos/professor para o local das aulas expositivas.

O quinto passo foi definir que nas 17 semanas em que estariam nas Unidades de Saúde, cada equipe de 3 alunos deveria redigir um "Diário de Campo" (um instrumento didáticopedagógico muito usado na Antropologia), relatando suas impressões, descobertas e experiências nos Serviços. A definição de 3 alunos por Unidade objetivou o aprendizado a partir 
de um trabalho cooperativo e solidário, dar mais segurança aos alunos, não permitir que o trabalho ficasse concentrado em um ou outro aluno, o que, geralmente ocorre, quando o grupo é muito grande. O número estabelecido também levou em consideração o trabalho dos profissionais que dariam supervisão aos estudantes e a capacidade instalada dos Centros de Saúde/PSFs. Coerentemente, este trabalho grupal de 03 alunos foi também utilizado, quando das atividades em sala de aula.

O sexto passo foi definir a supervisão semanal do professor aos trabalhos dos alunos nas Unidades de Saúde. A cada sexta-feira, o professor dirigia-se a uma Unidade distinta, após haver, previamente, informado aos gerentes dos Centros/PSF. Na Unidade, o professor reiterava aos gerentes a proposta anteriormente discutida e aprovada no Colegiado Diretivo da SEMUSA, esclarecia as dúvidas que porventura houvessem, conhecia o Centro de Saúde/PSF, realizava com os estudantes as atividades previstas, procurava ver outras açōes que poderiam ser desenvolvidas e que não haviam sido definidas, anteriormente, etc. Ao final do curso, o professor havia visitado 16 das 17 Unidades onde a inserção dos alunos foi feita.

O sétimo passo foi a elaboração de uma carta de apresentação assinada pelo professor e pelo responsável pelas ações básicas da SEMUSA, endereçada aos gerentes e que continha os nomes dos alunos destinados à unidade, as atividades prioritárias que realizariam: investigação epidemiológica de natimortos e/ou nascidos vivos e/ou enfermidades transmissiveis, visitas domiciliar para conferencia do teste do "pezinho", levantamento de morbidade ambulatorial ("CID"), controle de cartão de vacina, levantamento epidemiológico de desnutrição (todas estas práticas rotineiras das unidades) e o acompanhamento de outras atividades executadas, ainda que não com enfoque epidemiológico, como observação do trabalho com grupos de hipertensos e diabéticos.

O oitavo passo foi a monitorização das ações dos alunos nas Unidades de Saúde. Em todo inicio das aulas expositivas desenvolvidas no INESP procurou-se saber como haviam transcorrido as atividades matinais nas Unidades, o que haviam realizado, quais problemas enfrentados, como haviam transcorrido as relações com o pessoal da Unidade, etc. A partir dai esclarecia-se os limites e as possibilidades das açöes da/na Unidade e, principalmente, buscavase fazer o vinculo entre a experiência prática vivida com os conceitos teóricos ensinados em sala de aula, procurando com isto superar a tăo decantada dicotomia "Teoria-Prática".

Ao término do semestre relatou-se aos 53 alunos o trabalho realizado/o artigo produzido e manifestou-se lhes a disposição em encaminhá-lo para publicação. Foi apenas solicitado pelos alunos que nas poucas falas transcritas o anonimato fosse respeitado. E assim o foi.

\section{RESULTADOS} especificos

Os resultados ora apresentados procuram ter por referência os objetivos gerais e

\section{EM RELAÇÃO AO CONTEÚDO CURRICULAR}

Este foi desenvolvido no tempo previsto e respeitando-se, integralmente, o programa estabelecido. O conhecimento adquirido pelos alunos foi avaliado por distintas maneiras. $\mathrm{Na}$ metade do curso foi dada uma prova em classe, respondida pelas equipes de 03 estudantes tendo como foco um texto publicado na "Folha de S. Paulo", de 24 de Outubro de 1999, sob o titulo de "O Câncer da próstata e o motel da praia do Francês", de autoria do Professor Titular de urologia da Escola Paulista de Medicina, dr. Miguel Srougi. Sobre este texto foram feitas perguntas que exigiam que os alunos tivessem entendido conceitos epidemiológicos até então ensinados. A opção por um texto da imprensa leiga objetivou demonstrar aos alunos que a Epidemiologia não é uma propriedade da Academia, mas, pelo contrário, está presente no cotidiano das 
pessoas. O trabalho, que foi realizado em grupo em razão dos principios pedagógicos anteriormente expressos, alcançou plenamente seus resultados.

Uma segunda avaliação baseou-se na apreciação dos "Diários de Campo", preenchidos por cada equipe de 3 alunos, onde procurou-se verificar o trabalho dos alunos realizados no periodo passado nas Unidades. Seu registro, suas análises e conclusões foram objeto de apreciação crítica.

Uma terceira avaliação centrou-se nas atividades desenvolvidas nas Unidades correlacionando-as com os conceitos epidemiológicos desenvolvidos em classe. Procurou-se saber como os alunos explicariam o Processo Saúde-Doença a partir das atividades de caráter epidemiológico desenvolvidas nas Unidades (controle de vacinas, visitas às familias de natimortos e nascidos vivos, controle do teste do "Pezinho", CID, etc).

Buscou-se, também, determinar a imagem que os alunos tinham antes e após a estada nestas semanas nas Unidades de Saúde. O que mudou nos alunos após estas vivências de campo e de sala de aula foi outro objeto desta avaliação. Como não eram questões valorativas ("de certo e errado"), as respostas dos alunos permitiram responder a alguns dos objetivos especificos enunciados.

A quarta avaliação centrou-se em aspectos puramente técnicos e objetivou que as equipes de 03 alunos analisassem e interpretassem corretamente dados estatisticos produzidos por Serviços e a partir dai apresentassem apreciações de tendências.

As avaliações procuraram ser integrativas, não artificiais, vinculando teoria e prática, com possibilidades de serem reproduzidas e com gradação das dificuldades.

\section{EM RELAÇÃO AO MÉTODO DE ENSINO-APRENDIZAGEM ESCOLHIDO}

Seguindo-se os passos da metodologia traçada, a inserção dos alunos deu-se a contento. Através das questões colocadas nas provas e, inclusive, em avaliações sobre a disciplina a inserção precoce dos alunos foi totalmente aprovada por eles. Isto não quer dizer que criticas não houve no processo ensino-aprendizagem. As criticas se distribuiram nos seguintes pontos:

- Para alguns a carga horária da aula teórica foi pouca.

- Para outros as atividades nas Unidades foram muito rotineiras.

- Para 2 dos 17 grupos de alunos, a atenção das equipes das Unidades foi aquém do esperado. Os motivos alegados variaram desde desinteresse à sobrecarga de trabalho e férias de funcionários.

- Para outros, a concentração das atividades da disciplina nas sextas-feiras levaram a que atividades que rotineiramente não eram realizadas nestes dias não fossem apreciadas pelos alunos.

No entanto, todos os alunos foram unânimes em afirmar a importância deste primeiro contato com o Serviço de Saúde. Unanimidade, também, se deu na mudança da imagem do Serviço de Saúde que de uma visão negativa, de uma instituição pouco comprometida com o trabalho e com a população passou a ser considerada e respeitada pelos alunos. Viu-se, também, que as Unidades não realizam somente ações de combate a doença mas também de estimulo a saúde. Reconheceu-se o esforço do Serviço em sua relação com a população. Compreendeuse o processo Saúde-Doença, diferenciando-se, inclusive, o que é visto como "Saúde" e o que é "Doença" nas Unidades.

Todos estes comentários encontram-se registrados nos "Diários de Campo" e nas provas dos alunos.

\section{DISCUSSÃO}

A discussão, segundo De la Maza (1992), é o exame atento e particular de uma matéria. 
Sendo assim, a investigação participante (técnica, também de ordem antropológica), que realizou-se permitiu analisar alguns dos "Resultados" e responder a algumas das questões colocadas na "Introdução".

A primeira resposta que pode-se dar é que a inserção de estudantes universitários nos Serviços de Saúde como método de ensino-aprendizagem é factivel e é necessária para a compreensão do processo Saúde-Doença, do papel de cada profissional no trabalho em equipe, e tratando-se de um serviço público, do papel deste serviço no sistema de saúde. Esta inserção permite, também, a compreensão das potencialidades e limites da Epidemiologia nas ações de saúde. Estas conclusões ainda que tratadas em outro contexto e com um grupo menor e em fase mais adiantada de sua formação já foi comentada por Cassiani, Riccie Souza (1998) e já defendida por Mello (1970) há tres décadas, mas infelizmente poucas vêzes levadas à prática em fases iniciais da formação em enfermagem.

A segunda questão é de que a inserção tanto pode ser precoce como não. Quando se define com muita clareza e precisão as competências e limites da atuação dos estudantes ("o que pode e não se pode fazer") nos Serviços de Saúde, a inserção nunca será precoce, pois estará adaptada à capacidade do aluno. Tal correlação não foi encontrada nas bases de dados consultadas (Medline, Lilacs, BDENF, etc) e nos pareceu um dado importante descoberto nesta investigação.

O inicio desta inserção depende, primeiramente, da vontade política dos envolvidos. Em segundo lugar das condições materiais e ambientais que se oferecem para a inserção. No caso de Divinópolis, além da vontade política, a estrutura viária da cidade permite um fluxo fácil de e/ para os Serviços de Saúde; os Centros de Saúde/PSFs comportam as equipes de 3 estudantes que para cada um deles se destinaram; os recursos humanos qualificados da SEMUSA potencializam a supervisão dos estudantes. Necessário se faz a compreensão ideológica por partes dos profissionais das unidades e dos alunos do que representa este trabalho de inserção precoce e suas conseqüências politicas. Esta compreensão permitiria o aprimoramento do trabalho.

A questão da dicotomia "Teoria-Prática", tão bem discutida em tese apresentada a Universidade do Rio de Janeiro por Caldeira (1992), na avaliação feita, foi superada na presente investigaçào com o método de ensino-aprendizagem aplicado. Reitera-se que é fundamental haver no curso um tempo e espaço destinado à reflexão. Realizar todo este processo em serviço não parece tão produtivo visto que a demanda constante que o Serviço apresenta, pode afetar a concentração dos alunos.

O aprimoramento dos Serviços de Saúde pela contribuição dos alunos poderia ser feito através da realização de trabalhos de epidemiologia descritiva e estudos de epidemiologia analítica. Os estudos de epidemiologia analitica (estudos transversais, prospectivos e retrospectivos) foram desenvolvidos em algumas Unidades pelos alunos, com resultados relevantes. A sistematização destas práticas, dentro do programa do curso, para serem realizadas em todas as Unidades poderiam aprimorar estes Serviços e contribuir positivamente, pois sendo intensa a demanda de pacientes aos Centros e PSFs, os funcionários que poderiam realizar estes trabalhos são pressionados a realização de outras atividades menos reflexivas. Este aprimoramento do curso é um papel que cabe, ao professor responsável e aos seus alunos.

O fato desta experiência ter sido desenvolvida em 17 Unidades de Saúde no dia a dia do Serviço superou o aspecto de artificialidade e de "experiência piloto" em que muitas vezes se transforma um projeto educativo e investigativo, como inclusive é relatado por Locato, Carvalho e Carvalho (1981) e Barbosa (1996).

Uma discussão que, certamente, valeria uma reflexão mais profunda, seria sobre o que provocou a mudança da imagem que os estudantes tinham dos serviços públicos. Seria o conhecimento das dificuldades dos trabalhadores destes serviços ? Seria a identificação com a profissão de seus pares, a iniciação na construção de uma identidade, como se de repente 
deixassem de ser "estudante" para ser "profissional"? Como um grupos de alunos colocou no "Diário de Campo": “... já fazemos parte da equipe do posto !!!".

Esta discussão, realizada em outro contexto por Merighi e Bonadio (1998) exigiria um aprofundamento da investigação, impossivel no momento.

\section{CONCLUSÃO}

Sendo a conclusão, segundo Castell (1986), a ação de resolver-se sobre o que se há tratado, afirmariamos, primeiramente, que a inserção precoce de estudantes universitários nos Serviços de Saúde como Método de Ensino-Aprendizagem cumpre um papel ideológico fundamental na formação de estudantes mais conhecedores de nossa realidade, mais criticos e atuantes. E que sempre que se estabeleça com muita clareza e precisão o que o aluno pode ou não pode fazer, levando-se, obviamente, em consideração o seu conhecimento, nunca a inserção do aluno poderá ser considera como precoce; pelo contrário, adequada e pertinente a sua formação e ao trabalho futuro.

SUMMARY: The authors evaluated the actions of Nursery School students in health services as a Teaching-Learning Method. Fifty-three students of the first year of Nursery School studying epidemiology were putted in seventeen Health Centers of Divinópolis Healt System during five months, one time by week, to learning the discipline. The researchers concluded that when the actions and limits of the student practices are clearly defined never the university student's use in Health Services will be a mistake.

KEYWORDS: evaluation, health services, nursery

RESUMEN: Los autores analizan la inserción de alumnos de Epidemiologia en los Servicios de Salud como método de ensenãnza. El estudio se desarrolló en 17 centros de salud con un total de 53 alumnos, durante 5 meses, con una frecuencia de un turno diario semanal, en Divinópolis, ciudad de Minas Gerais, Brasil. Se concluye que si se definen con precisión las competencias y límites de actuación de los estudiantes la inserción nunca será precoz, pues estará adaptada a la capacidad del alumno.

PALABRAS CLAVE: evaluación, académicos de Enfermeria, servicios de salud

\section{REFERÊNCIAS BIBLIOGRÁFICAS}

BARBOSA, M. L. D. Estudo da percepção do aluno da Escola de Enfermagem da Universidade Federal de Minas Gerais sobre o processo de sua formação acadêmica. Belo Horizonte, 1996. 136. p. Dissertação (Mestrado) - Escola de Enfermagem da Universidade Federal de Minas Gerais.

BATISTA, N. A.; SILVA, S. H.S. O ensino médico: sua trajetória no cenário nacional. In: Professores de Medicina. São Paulo: Loyola, 1998. p. 19-44.

CALDEIRA, V. P. Estágio extra-curricular - opção ou obrigação ?: uma contradição a ser superada. Rio de Janeiro, 1992. 156. p. Dissertação (Mestrado) - Universidade do Rio de Janeiro.

CASSIANI, S. H. D. B.; RICCI, W. Z.; SOUZA, C. R. A experiência do programa especial de treinamento na educação de estudantes de graduação em enfermagem. Rev Latinoam enfermagem, v. 6, n. 1. p. 63-69, 1998. 
CASTELL, R. Diccionario de la lengua española. Barcelona: EMEGE, 1986.

CORREA, E. J. Alteração curricular do curso de medicina da UFMG. Belo Horizonte. Rev Med Minas Gerais, v. 1, n. 2, p. 106-111, 1991.

DE SALAZAR, L. Escuelas promotoras de salud: resultado de alianzas estratégicas entre la academia, el gobierno municipal y la comunidad. Faculdad de Salud, Universidad del Valle. Centro para el Desarrollo y Evaluación de tecnologia en Salud. Cali: CEDETES, 1999.

DE LA MAZA, S. S. Diccionario etimológico de la lengua castellana. Madrid: AL. Mateos S. A., 1992.

LOCATO, M. L. Carvalho HC, Carvalho HM. Uma experiência de ensino em escolas de primeiro grau de Alfenas. Rev Bras Enferm., v. 34, n. 3, p. 327-32, 1981.

MELLO, J. Preparo no curso de graduação, para a integração do enfermeiro recém-graduado na vida profissional. Rev bras enfermagem, v. 23, n. 3/6, p. 45-56, 1970.

MERIGHI, M. A. B,; BONADIO, I. C. A vivência de alunos de graduação em enfermagem na assistência à saúde da mulher em uma comunidade de baixa renda: uma abordagem fenomenológica. Rev Esc Enfermagem USP, v. 32, n. 2, p. 109-116, 1998. 